\title{
Journal of Materials Research announces appointment for Advanced Metallic Materials
}

\author{
Gary Messing ${ }^{1}$ \\ ${ }^{1}$ Editor-in-Chief, Journal of Materials Science
}

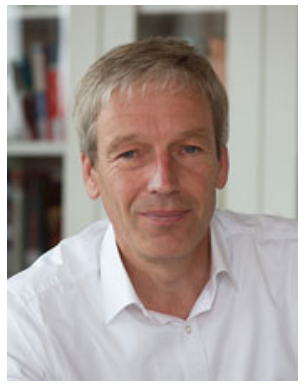

Journal of Materials Research Editor-in-Chief Gary Messing is pleased to announce the appointment of Dr. Mathias Göken as Associate Editor of Advanced Metals. In Dr. Messing's assessment, "Dr. Göken brings extensive expertise and experience in novel metallic materials and processing. His contributions in nanocharacterization and development of novel metals aligns well with the advanced materials focus of JMR.”

Dr. Göken is Chair Professor at Friedrich-AlexanderUniversity Erlangen-Nürnberg (FAU) and head of the Institute for General Materials Properties. His research focuses on the mechanical behavior and microstructure of advanced metallic materials, coatings and thin films, for example $\mathrm{Ni}$ and Co-base superalloys, TiAl alloys, ultrafine-grained/nanomaterials and lamellar composites. He has participated in research showing that lamellar metallic composites (LMCs), with such exceptional properties as significantly higher strength and improved ductility or fatigue resistance, can be produced on a large scale by accumulative roll bonding (ARB). Dr. Göken's research group is developing nanomechanical testing of individual phases coupled with in situ and ex situ characterization at all length scales by TEM/SEM techniques, AFM, FIB and atom probe tomography. Dr. Göken's work has appeared in more than 230 ISI journal publications, with an h-index of more than 40 (Web of Science).

Dr. Mathias Göken received a diploma degree in Physics from the University of Münster, his Ph.D. in fracture mechanics at the Max Planck Institute for Iron Research, Düsseldorf, and a "Habilitation degree" at University of Saarland. Dr. Göken was a visiting Feodor-Lynen fellow at Stanford University in the W.D. Nix group. In 2001, he received the prestigious Masing-award from the German Society for Materials Research, DGM in recognition of his work on small-scale mechanical behavior. Since 2008 he has also been a member of the Board of Directors of the Central Institute for New Materials and Processing (ZMP, Fürth) and served as spokesperson of the Department for Materials Science and Engineering. In 2008 he was the founding director of the Erlangen Center for Nanoanalysis and Electron Microscopy (CENEM) at FAU. Prior to accepting the Associate Editor role, Dr. Göken had served as a Principal Editor with JMR since 2016. 